\title{
Occupational inhalation injury by Hydrogen Sulfide causing multi organ failure $-A$ case study
}

\author{
Karishma Shamarukh ${ }^{1}$, Mohammad Omar Faruq ${ }^{2 *}$, Nasrin Jahan ${ }^{1}$, Amina Sultana ${ }^{3}$, Ridwan Naim Faruq ${ }^{4}$
}

\begin{abstract}
:
Hydrogen sulfide is a notorious agent known to cause serious injuries in the occupational field. We are going to discuss a case of a 20 years old male working in a effluent treatment plant in Savar, Bangladesh who accidentally entered the fume room and was exposed to the toxic gas. He lost consciousness and was brought to our care from a local hospital after endotracheal intubation condition. He was found in state of unconsciousness grade III on admission to our ICU. His brain CT scan revealed diffuse cerebral edema. Chest X-ray revealed finding suggestive of diffuse pneumonitis. Cardiology evaluation suggested Toxic cardiomyopathy as his high sensitive Troponin I was very high on admission ( $2037 \mathrm{ng} / \mathrm{L}$ ). Supportive care was given in the form of mechanical ventilation, antibiotics, anticonvulsant and anti-ischemic medications. Patient regained consciousness on day 10 after admission and gradually improved clinically. By the end of the month of stay in hospital he was significantly improved.
\end{abstract}

Key words : Effluent treatment plant, Hydrogen Sulphide, Chemical Pneumonitis, Toxic Cardiomyopathy, Toxic encephalopathy.

\section{Introduction}

The principal industrial source of Hydrogen Sulfide $\left(\mathrm{H}_{2} \mathrm{~S}\right)$ is as a byproduct in the purification of natural and refinery gases. It is also a by-product of pulp and paper manufacturing and carbon disulphide production. It is used as an intermediate in manufacturing processes of certain chemical (e.g. sulphuric acid). Human exposure to exogenous $\mathrm{H}_{2} \mathrm{~S}$ is principally via inhalation with rapid absorption. $\mathrm{H}_{2} \mathrm{~S}$ is metabolized through three pathways: oxidation, methylation, and reactions with metalloproteins or disulphide-containing proteins. Oxidation in the liver is the major detoxification pathway, forming thiosulphate, which is then converted to sulphate and excreted in the urine. The methylation pathway also serves as a detoxification route. The toxicity of $\mathrm{H}_{2} \mathrm{~S}$ is a result of its reaction with key metabolic metalloenzymes. In the mitochondria, cytochrome oxidase (the final enzyme in the respiratory chain) is inhibited by $\mathrm{H}_{2} \mathrm{~S}$. This disrupts the electron transport chain and impairs oxidative metabolism which particularly impacts nervous and cardiac tissues (both are tissues with high oxygen demand and rely on oxidative metabolism). In the central nervous system, this effect may result in unconsciousness or even death from respiratory arrest. High flow oxygen is generally used to treat victims of

\footnotetext{
1. Senior House Officer, General ICU United Hospital Ltd.

2. ChiefConsultant, General ICU \& Emergency, United Hospital Ltd.

3. Junior Consultant, General ICU, United Hospital Ltd

4. Former Lecturer, Ibrahim Medical College.
}

*Corresponding Author:

Prof Mohammad Omar Faruq

Chief Consultant, General ICU \&Emergency

United Hospital Ltd, Dhaka 1212, Bangladesh.

E mail: faruqmo@yahoo.com

Cell : +88 01674999897
$\mathrm{H}_{2} \mathrm{~S}$ poisoning although other treatments such as hyperbaric oxygen and parenteral administration of a methaemoglobin inducing agent (such as sodium nitrite) have also been reported. $\mathrm{H}_{2} \mathrm{~S}$ is acutely toxic with fatalities associated with concentrations in excess of $500 \mathrm{ppm}$ (part per million). It has a very low odor threshold $(0.008 \mathrm{ppm})$ but odor perception is lost at concentrations of 150-250 ppm adding to the danger of high level exposures as they may not be recognized by smell by the individual. In Europe, there is a workplace exposure limit $8 \mathrm{~h}$ Time Weighted Average( TWA) of $5 \mathrm{ppm}$ with a short-term (15-min) exposure limit of $10 \mathrm{ppm} .{ }^{1}$

Despite important advances in the care of patients with inhalation injury, which continues to be largely supportive, morbidity and mortality remain high ${ }^{2}$. Inhalation injury can feature supraglottic thermal injury, chemical irritation of the respiratory tract, systemic toxicity due to agents such as carbon monoxide and cyanide, $\mathrm{H}_{2} \mathrm{~S}$, Sulphur dioxide, or a combination of these insults. Sometimes biogas and other toxic materials also contribute to these insults. The resultant inflammatory response may cause higher fluid resuscitation volumes, progressive pulmonary dysfunction, prolonged ventilator days, increased risk of pneumonia, and acute respiratory distress syndrome (ARDS) ${ }^{3,4}$.

\section{Case study:}

Our patient was 20 years old male working in an Effluent treatment Plant (ETP) in Savar. He had no co-morbidities and was an occasional smoker. He was accidentally exposed to waste fumes while working in the ETP and thereafter lost consciousness. According to the Chinese technician in charge of operation of the ETP patient was exposed to fumes predominantly containing hydrogen sulfide and patient was not wearing protective gas mask which was supplied to the workers. Patients coworkers found him unconscious but were unable to state the duration of loss of consciousness. Eventually he was taken to a local hospital in Savar. After initial management they found him to be in severe respiratory 
distress and he was intubated ensuring mechanical ventilation. Then he was brought to United Hospital ICU for further management.He was in state of unconsciousness grade III. Chest X-ray revealed finding suggestive of chemical pneumonitis (Fig-1). His ECG was unremarkable. Cardiology evaluation suspected Toxic cardiomyopathy as evidenced by raised high sensitive TroponinI level which was 2037ng/L (normal value: 0 and $0.4 \mathrm{ng} / \mathrm{mL}$ ) on admission, there after the second Troponin I was $3170 \mathrm{ng} / \mathrm{L}$. The echocardiogram revealed no regional wall motion abnormality and an EF of $58 \%$. Patient was unconscious and only responded to pain. His brain CT scan revealed diffuse edema (Fig-2). He was restless at times and also experienced seizure which was generalized and persisted for 2 to 3 minutes time to time. Supportive care was given in the form of mechanical ventilation, antibiotics, anticonvulsant and anti-ischaemic drugs as needed. His plasma lactate was $5.71 \mathrm{mmol} / \mathrm{L}$, CRP $142 \mathrm{mg} / 1$.Procalcitonin was $41.83 \mathrm{ng} / \mathrm{ml}$. His total WBC count increased over time starting from $8000 / \mathrm{uL}$ and rising up to $25000 / \mathrm{uL}$. With regular physiotherapy and proper observation he began to show slight improvement each day. Chest $x$-rays at $6^{\text {th }}$ and $7^{\text {th }}$ day of treatment compared to Day I of admission showed significant improvement in lung condition (Fig 3). He gradually began to responding distinctly to voice by $10^{\text {th }}$ day.

Later he was taken to a government medical facility for further care and rehabilitation. He gradually improved and at the end of a month he began to move limbs on command and could breathe in room air as well.

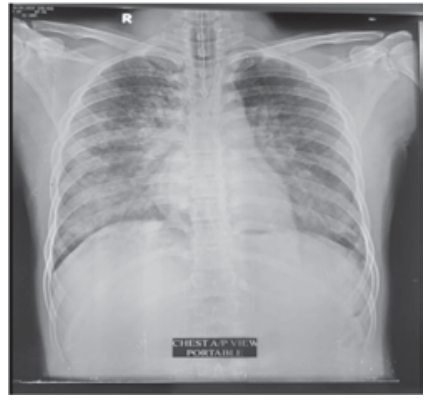

Fig1:

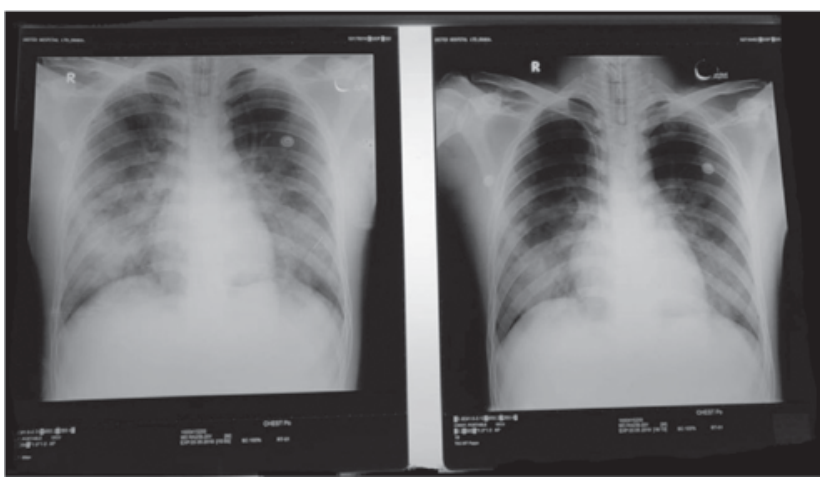

Fig 3:

\section{Discussion:}

Inhalation injury is actually almost a straightforward diagnosis from the history. The most challenging part is the timed management and supportive care. The damage ranges from moderate to extensive, affecting different organs in the body. The degree of inhalation injury is variable and is dependent on several factors: the inhaled gas components, the presence of particulate matter (soot), the magnitude of the exposure, and individual host factors such as underlying lung disease and inability to flee the incident ${ }^{5}$. Historically, it was speculated that the combustion of certain materials, such as noncommercial polyurethane foam, resulted in the formation of a neurotoxin; however, newer material testing methods revealed most smoke toxicity can be explained by a small number of toxic gases exerting their effects through asphyxiation, systemic toxicity, or direct effects on respiratory tissue $^{5}$. The toxic mechanism of hydrogen sulfide comprises inactivating cytochrome oxidase in mitochondria and then preventing the cellular metabolism of oxygen. Via this mechanism, hydrogen sulfide can induce hypoxic brain damage and hypoxic cardiac damage as well as mucosal damage ${ }^{6}$.

Lead acetate test papers can be used for fast \& easy confirmation of $\mathrm{H}_{2} \mathrm{~S}$ in air or water down to as low as $3 \mathrm{ppm}$ but is unfortunately not available in our country?

Many studies have been conducted to find a proper treatment for $\mathrm{H}_{2} \mathrm{~S}$ toxicity. One study has hypothesized that Methemoglobin could improve the recovery of $\mathrm{O}_{2}$ utilization by the mitochondria, following the cessation of hydrogen sulfide intoxication via its specific ability to combine soluble $\mathrm{H}_{2} \mathrm{~S}$, but also possibly though its anti-nitric oxide effects ${ }^{8-10}$.

Till now no ideal antidote could be identified for $\mathrm{H}_{2} \mathrm{~S}$ sulfide poisoning and treatment is largely supportive. Two cyanide antidotes: hydroxocobalamin and sodium nitrite have been tested as sulfide antidotes; hydroxocobalamin binds sulfide and nitrite generates both methemoglobin, which binds sulfide, and nitric oxide, which could displace sulfide from cytochrome $\mathrm{C}$ oxidase ${ }^{6}$.

Based on the similarities in cyanide and $\mathrm{H}_{2} \mathrm{~S}$ toxicity, induced methemoglobinemia may be used in hydrogen sulfide toxicity. Methemoglobin acts as a scavenger, and it has a stronger affinity to $\mathrm{H}_{2} \mathrm{~S}$ than to cytochrome oxidase. $10 \mathrm{~mL}$ of $3 \%$ sodium nitrite is administered IV over 2-4 minutes (adult dose) then a methemoglobin level 30 minutes after administration of antidote is obtained. However, there is a lack of research evidence supporting efficacy of this antidote t1-12. $^{12}$.

Patients who have suffered significant exposure (i.e., anything other than chronic low-level exposure with mucous membrane irritation) should be admitted to the intensive care unit. Patients who are unresponsive to intravenous nitrites or who have persistent or delayed neurologic sequelae should be considered for hyperbaric oxygen therapy (HBO). Anecdotal reports indicate a salutary effect ${ }^{13}$.

Our patient showed evidence of lung damage in the form of 
chemical pneumonitis on $\mathrm{X}$ ray. A lot of factors potentiate local cellular damage and the loss of hypoxic pulmonary vasoconstriction caused by $\mathrm{H}_{2} \mathrm{~S}$. The loss of hypoxic pulmonary vasoconstriction causes bronchial blood flow to increase by a factor of 10 within 20 min of inhalation injury. Reactive Oxygen Species (ROS) may also induce mitochondrial dysfunction and cellular apoptosis ${ }^{15}$. Tissue factor expressed by damaged respiratory epithelial cells and alveolar macrophages initiates the extrinsic coagulation cascade, disrupting pro- and anti-coagulant alveolar homeostasis ${ }^{14}$.

Myocardium needs to extract maximum available oxygen in blood even at resting state, due to continuous and high oxygen demand. Therefore myocardium could be injured by increased oxygen demand and decreased oxygen supply. However, hydrogen sulfide can cause myocardium injury despite normal coronary blood flow, because it prevents myocardial cell form using oxygen for energy generation ${ }^{15-16}$.

A few cases of myocardial damage after exposure of $\mathrm{H}_{2} \mathrm{~S}$ has been reported ${ }^{16}$. Massive myocardial necrosis after exposure to hydrogen sulfide (at $>500 \mathrm{ppm}$ for more than $40 \mathrm{~min}$ ) confirmed through postmortem autopsy and two victims without autopsy, one of whom died following massive cardiogenic pulmonary edema and the other died of acute cardiacinfarction two months after exposure to the gas has been described previously ${ }^{12}$. Recently two victims also presented with abnormal ECG with elevated ST segment in the left precordial leads ${ }^{17}$. One surviving case has shown abnormal ECG such as a posterolateral myocardial ischemic changes, which had returned to normal gradually ${ }^{17}$. Our case has shown relatively good recovery from myocardial injury.

Occupational health professionals, responsible for safeguarding health in the workplace, should make an adequate assessment of the risks attributable to health hazard and should promote and protect the health and safety of workers through careful risk management based on continuous occupational training and information. All patients should be discussed with the local poison center if available and/or a medical toxicologist in order to minimize the risk of progression of any injury resulting from such accidental exposure to toxic fume.

\section{References:}

1. Case studies of hydrogen sulphide occupational exposure incidents in the UK. https://www.sciencedirect.com/science/article/pii/S0 378427414012922
2. Albright JM, Davis CS, Bird MD, Ramirez L, Kim H, Burnham EL et al. The acute pulmonary inflammatory response to the graded severity of smoke inhalation injury.Crit Care Med. 2012;40:1113-21.

3. Dries DJ, Endorf FW. Inhalation injury: epidemiology, pathology, treatment strategies. Scand J Trauma Resusc Emerg Med. $2013 ; 21: 31$

4. Endorf FW, Gamelli RL. Inhalation injury, pulmonary perturbations, and fluid resuscitation. J Burn Care Res. 2007;28:80-3. doi:10.1097/bcr.0b013e31802c889f

5. Walker PF, Buehner MF, Wood LA, Boyer NL, Driscoll IR, Lundy $\mathrm{JB}$ et al. Diagnosis and management of inhalation injury: an updated review.Critical Care. $2015 ; 19: 351$.

6. Smith RP, Gosselin RE. Hydrogen sulfide poisoning. J. Occup. Med. 1979; 21: 93-97

7. Hydrogen Sulfide Test - Principle, Procedure, Uses and Interpretation Last updated: June 14, 2019 by Sagar Aryal.https://microbiologyinfo.com/hydrogen-sulfide-test/

8. Buehler PW, Alayash AI. All hemoglobin-based oxygen carriers are not created equally. Biochimicaetbiophysicaacta 2008;1784(10):1378-1381.

9. Rohlfs RJ, Bruner E, Chiu A, Gonzales A, Gonzales ML, Magde D et al. Arterial blood pressure responses to cell-free hemoglobin solutions and the reaction with nitric oxide. The Journal of biological chemistry. 1998;273(20):12128-12134.

10. Smani Y, Fifre A, Labrude P, Vigneron C, Faivre B. Pharmacological and physicochemical factors in the pressor effects of conjugated haemoglobin-based oxygen carriers in vivo. Journal of hypertension. 2007;25(3):599-608.

11. Toohey J.I. Hydrosulfide derivatives of Cobalamins.J. Inorg. Biochem.1993; 49:189-199.

12. Guidotti T.L. Hydrogen sulphide. Occup.Med. 1996;46:367-371.

13. Pearce L.L., Bominaar E. L., Hill B. C., Peterson J. Reversal of cyanide inhibition of cytochrome $\mathrm{c}$ oxidase by the auxiliary substrate nitric oxide: an endogenous antidote to cyanide poisoning? J. Biol. Chem. 2003;278: 52139-52145.

14. Smith R.P., Kruszyna R., Kruszyna, H. Management of acute sulfide poisoning. Effects of oxygen, thiosulfate, and nitrite. Arch. Environ.1976; Health 31: 166-169.

15. Sureshbabu A, Bhandari V. Targeting mitochondrial dysfunction in lung diseases: emphasis on mitophagy. Front Physiol. 2013;4:384. doi:10.3389/fphys.2013.00384

16. Ago M, Ago K, Ogata M. Two fatalities by hydrogen sulfide poisoning: variation of pathological and toxicological findings. Leg. Med.2008; 10: 148-152.

17. Gregorakos L, Dimopoulos G, Liberi S, Antipas G. Hydrogen sulfide poisoning: Management andcomplications. Angiology. 1995; 46: 1123-31. 